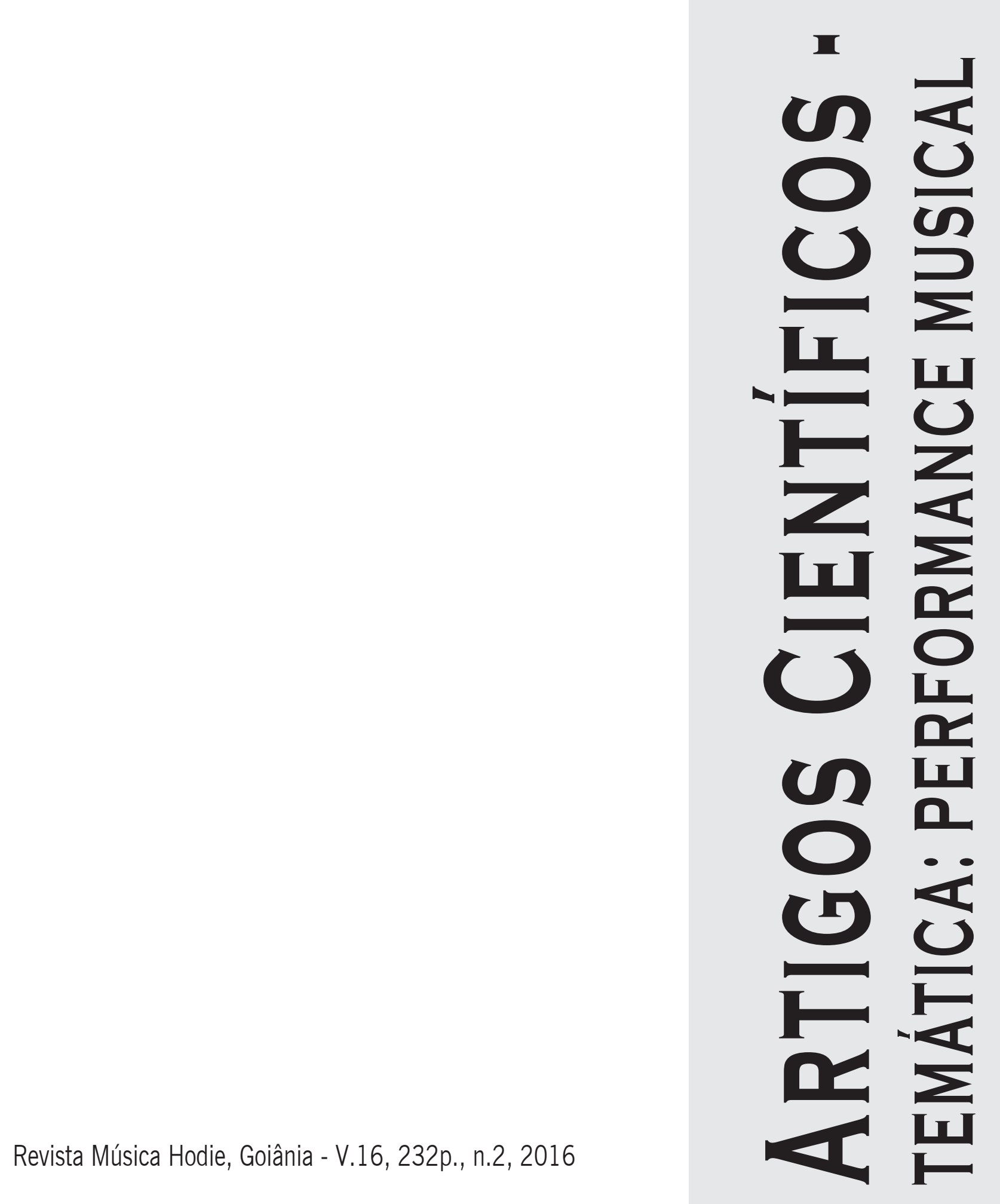




\title{
O processo de digitação ao violão para o Prelúdio BWV 997 de Johann Sebastian Bach
}

\author{
Maurício Nunes (EMBAP/Universidade Estadual do Paraná, Curitiba, PR, Brasil) \\ mauricio.m.nunes@hotmail.com \\ Alisson Alípio (EMBAP/Universidade Estadual do Paraná, Curitiba, PR, Brasil) \\ alissonalipio@gmail.com
}

\begin{abstract}
Resumo: Este trabalho tem como objetivo apresentar uma digitação para o Prelúdio BWV 997 de Johann Sebastian Bach. Identificamos e classificamos os motivos presentes na obra. Em seguida, apresentamos uma digitação para os mesmos, que refletisse lógica e unidade e, consequentemente, para todo o Prelúdio. Assim, comparamos as edições, Frank Koonce e Frédéric Zigante, que utilizamos como edições de referência, abordamos algumas problemáticas ao digitar a obra de Johann Sebastian Bach para violão e concluímos com a elaboração de uma edição prática da referida obra, por entendermos que a digitação também é um elemento interpretativo.

Palavras-chave: Repertório de violão; Digitação ao violão; Edição de performance.
\end{abstract}

The guitar fingering process of BWV 997 Prelude composed by Johann Sebastian Bach

Abstract: This paper aims to present a fingering for Johann Sebastian Bach's Prelude BWV 997. We have identified and classified the motives existent on the work. Then we have presented some fingering for them, which reflects logic and unity and, consequently, to the entire Prelude. Thus, we have compared the reference editions, Frank Koonce and Frédéric Zigante, that were used as reference of editions, we have approached some problems concearning fingering Johann Sebastian Bach's work to guitar and then we finished with the elaboration of a practical edition of the work, because we believe that fingering is also an interpretative element.

Keywords: Guitar repertoire; Guitar fingering; Performance edition.

El proceso de digitación em la guitarra para el Prelúdio BWV 997 de Johann Sebastian Bach

Resumen: El trabajo tiene como objetivo presentar una digitación en lo Preludio BWV 997 de Johann Sebastian Bach. Identificamos y classificamos los elementos presentes en la obra. Entonces, para apresentear una digitación de los mismos que reflejan lógica y unidad y por lo tanto para todo el Preludio. Por lo tanto, las ediciones que comparan Frank koonce y Frédéric Zigante, que utilizamos como tema de referencia, se abordan algunos problemas en la digitaciones en la obra de Johann Sebastian Bach para guitarra y concluyen con la preparación de una edición práctica de ese trabajo, porque creemos que la digitación es también un elemento interpretativo.

Palabras clave: Repertório de la guitarra; Digitación en la guitarra; Edición de performance.

\section{Introdução}

A possibilidade de executarmos notas de mesma altura em regiões distintas ao longo do braço do violão faz com que o ato de digitar nesse instrumento seja sempre averiguado, questionado, e quando possível reelaborado por parte dos intérpretes devido aos vários critérios ou situações que aparecem na preparação de uma obra musical. Segundo Wolff (2001), "a escolha da digitação depende de diversos fatores: dificuldade técnica da obra, características individuais (anatomia das mãos, nível técnico, sonoridade do instrumento), estilo da obra [e] Interpretação (fraseado, articulação, timbre, etc.)"

De acordo com Wolff, pode-se entender que se tais critérios não forem levados em consideração e aprimorados durante o estudo de uma peça musical, podemos apresentar digitações equivocadas.

Porém, muitos dos equívocos surgem pelo fato de não considerarmos as diversas possibilidades interpretativas. Isto ocorre, às vezes, por falta de experiência musical, por utilizarmos as digitações presentes nas edições, ou porque buscamos o mesmo efeito sonoro obtido por algum intérprete. Tais situações, muitas vezes, são vividas por alunos iniciantes e sobre isso, (GILARDINO 1998 apud SILVEIRA FILHO 2004) afirma que: 
[...] vê com preocupação a receptividade das informações contidas em suas sugestões de execução, sobretudo com relação aos violonistas iniciantes. Afirma que se pudesse faria algumas mudanças editoriais, principalmente em relação a digitações. Destaca que muitas vezes, por pressão das editoras, suas indicações de digitação foram elaboradas em função do interesse de facilitar passagens, não representando possivelmente a melhor solução para problemas de execução de peças musicais. (GILARDINO, 1998, apud SILVEIRA FILHO, 2004, p. 9)

Sendo assim, devido às questões mencionadas anteriormente, diversas interrogações ocorrem sobre tal quesito. Entre essas surgem: Como cogitarmos uma digitação para as obras de Johann Sebastian Bach? O que abordar primeiramente ao elaborar digitações nas obras desse compositor?

\section{Revisão de literatura}

Atualmente, não há, ainda, um número relevante de pesquisas de cunho científico para a resolução dos problemas de digitação, sendo nítida a falta de discussão por parte da literatura do violão, entre docentes, discentes e fora do meio acadêmico (escolas de música e conservatórios).

Todavia, com a exceção de Wolff (2001), Alípio e Wolff (2010) e Alípio (2014) a maioria dos trabalhos identificados, como: os métodos para violão de Carlevaro (1979), Escuela de la guitarra exposición de la teoría instrumental, Barceló (1995), La Digitación Guitarrística, recursos pocos usuales e Fernandez (2000), Técnica mecanismo y aprendizaje: Una investigación sobre como llegar a ser guitarrista, abordam o tema digitação, nem sempre de maneira sistematizada, a ponto de criar uma metodologia. Devido a isso, acreditamos que muitos dos relatos sobre digitação, presentes nesses métodos, podem vir da própria experiência dos autores. Vejamos o que relata Contreras (1998): "os numerosos conselhos de [David Russell] me serviram para melhorar aspectos concretos da técnica instrumental, [...] conselhos que compartilhamos nos numerosos cursos em que nos encontramos”.(CONTRERAS, 1998, p. 9)

Já nos trabalhos da produção acadêmica verificou-se que o tema digitação é abordado por Silveira Filho (2004), nas Five Bagatelles de Willian Walton, Nunes (2007), no Ballet de Manuel Ponce, Orellana (2008), quando as compara nas duas edições da Fuga BWV 998 de Johann Sebastian Bach e apresenta sugestões para as mesmas e Santos (2009), que demonstra meios alternativos para realizar diversas passagens na peça musical Aquarelle de Sérgio Assad, utilizaram-se também de parâmetros técnicos de mão esquerda ${ }^{1}$ como: translado, dedo guia e dedo pivô, para solucionar os problemas interpretativos através da digitação. Sobre tais parâmetros Alípio (2014) descreve que:

Translado, [é] simplesmente, [...] qualquer situação pela qual o(s) dedo(s) se desloca(m) longitudinal ou transversalmente ou ambas de sua posição (ALÍPIO, 2004, p. 65), dedo guia, [é o] deslizamento de um dedo de um ponto ao outro, sobre uma mesma corda, sem intenção de produzir som. (ALÍPIO, 2004, p. 55), dedo pivô, [é] um dedo, que girando sobre si mesmo, permite a mudança de apresentação da mão esquerda mantendo a nota o qual corresponde e facilitando a colocação de uma nova posição. Funciona também como uma alavanca que prepara o movimento de outras demandas técnicas, como por exemplo, a contração e a sobre posição. (ALÍPIO, 2004, p. 54)

Conclui-se que, tanto nos métodos quantos nos trabalhos científicos, os autores, discorrem sobre o tema de maneira a solucionar problemas técnicos em obras, na maioria, originalmente escritas para o instrumento/violão. Os autores também expõem expectativas 
para que tal objeto de estudo possa ser abordado de uma maneira "profunda", pelo fato do instrumento possuir notas iguais em regiões distintas. A esse respeito Nunes (2007) diz que:

A [...] digitação é um elemento importante no aprendizado de uma obra, principalmente em um instrumento como o violão. Nesse instrumento existe a característica de podermos encontrar notas iguais em altura e regiões distintas, ao longo do braço do violão. Dessa forma, para elaborarmos uma digitação eficiente, é importante que haja uma constante revisão ao longo do estudo, experimentando diversas alternativas e soluções para os repetidos problemas que normalmente surgem na preparação de uma obra. (NUNES, 2007, p. 36)

\section{Referencial teórico}

Utilizamos como referencial os procedimentos baseados em Alípio e Wolff (2010), que identificaram e classificaram os motivos musicais, evidenciaram vozes implícitas, apresentaram uma transcrição para o violão e organizaram uma digitação de mão esquerda para a Ciaccona BWV 1004 em Ré menor de Johann Sebastian Bach, Colombo e Wolff (2005), que abordaram o estudo sobre articulação em música barroca através das ligaduras longa na Ciaccona BWV 1004 de Bach e sua adaptação em uma transcrição para o violão e Pires Jr. (1998), que escreve sobre o Exercício Integrado ao violão (EI) ${ }^{2}$ tratando de questões relacionadas à textualidade, perceptividade e tecnicidade.

\section{Metodologia}

O processo metodológico envolveu o levantamento de edições de referência sendo essas as edições para alaúde do arquivo de Hauser ${ }^{3}$ e violão de Frank Koonce (1989) e Frédéric Zigante (2001) onde inicialmente comparamo-las; identificamos e classificamos os motivos recorrentes na obra musical; estabelecemos critérios para executar/interpretar os motivos e, por conseguinte, elaboramos uma digitação para os motivos e consequentemente para o Prelúdio BWV 997 de Johann Sebastian Bach.

\section{O problema de digitação na obra para violão de Johann Sebastian Bach}

Por ser uma música "fundamentalmente orientada pela fala” e não ser original para o violão apresenta, muitas vezes, dificuldades de articulação. Para Harnoncourt "a música do período barroco é fundamentalmente orientada pela linguagem”, ou seja, a "fala” (HARNONCOURT, 1984, p. 42 apud COLOMBO, 2006, p. 35).

Outra dificuldade encontrada foi a elaboração de padrões digitacionais ao executar/ interpretar trechos análogos - devido à falta de idiomatismo. Segundo Alípio e Wolff "nem sempre é possível conciliar todos os critérios estabelecidos para se digitar uma obra" (ALÍPIO; WOLFF, 2010, p. 96).

Encontramos problemas relacionados ao prolongamento de notas - por causa da limitação física do instrumento. Para essa situação, Silveira Filho (2004) salienta que "em razão das possíveis limitações que a escala do violão oferece, a necessidade de efetuação de uma prolongação [de nota] pode acarretar limitações que envolvam outros elementos interpretativos" (SILVEIRA FILHO, 2004, p. 36). 
Outra peculiaridade é em relação à execução contrapontística devido à dificuldade de condução de vozes. Nunes, (2007), diz que "as características do violão impõem certas restrições. O principal problema da execução contrapontística para violão é a dificuldade da condução de vozes" (NUNES, 2007, p. 18).

\section{O Prelúdio BWV 997}

Este Prelúdio enquadra-se numa classe de peças características, que apresentam uma escrita improvisatória, ou seja, "livre", sem restrições a uma estrutura musical específica como a forma binária, ternária, sonata, rondó, etc. No entanto, identificamos alguns elementos em sua elaboração como: proporções simétricas, repetições de padrões motívicos, modulações e cadências que são reforçadas por trinados.

Por essa razão, dividimos a obra musical em quatro seções definidas como A - B C - CODA. A seção A do c. 1 ao 16 onde a peça musical apresenta seu motivo primário no acorde de Lá menor, a seção B do c. 17 ao 32 onde temos a reexposição do mesmo no acorde de Mi menor, em uma transposição real ${ }^{4}$, a seção C do c. 33 ao 53, o motivo apresenta-se variado no acorde de Ré menor e entendemos que ele está em apresentação retrógrada e a coda do c. 54 ao 56, que apresenta-se no acorde de Mi Maior e é predominantemente formada por movimento conjunto.

\section{Motivos}

Para elaborarmos as digitações na obra musical utilizamos os motivos classificados abaixo e a seguir apresentamos condições de digitações para cada um dos mesmos: 1) motivo por movimento escalar, 2) motivo por movimento escalar e arpejo com apojatura, 3) motivo por salto retórico ${ }^{5}$ seguido de movimento escalar, 4) motivo por bordadura seguido de salto melódico, 5) motivo por pedal ${ }^{6}$ e 6) motivo de ostinato em grau conjunto intercalado por salto retórico.

\section{0 processo digitacional}

\section{1) Motivo por movimento escalar}

Pelo fato do motivo apresentar-se por movimento escalar, optamos por executar a nota de passagem - segunda célula do primeiro tempo - por meio de ligado. Por entendermos que a execução da mesma em tal situação tornar-se-á mais "suave", proporcionando, assim, maior ênfase na execução da terceira célula do referido tempo, ou seja, na nota mais estruturada. Outra situação que julgamos favorável ao executarmos a nota de passagem em corda solta é o fato de proporcionarmos mais expressão ao quesito legato. Vejamos o relato de Wolff (2001): "geralmente usada em obras barrocas, a digitação cross string [ou campanella] distribui os graus conjuntos da escala em cordas diferentes, permitindo que várias notas contíguas da escala soem simultaneamente, favorecendo o legato na execução”. 

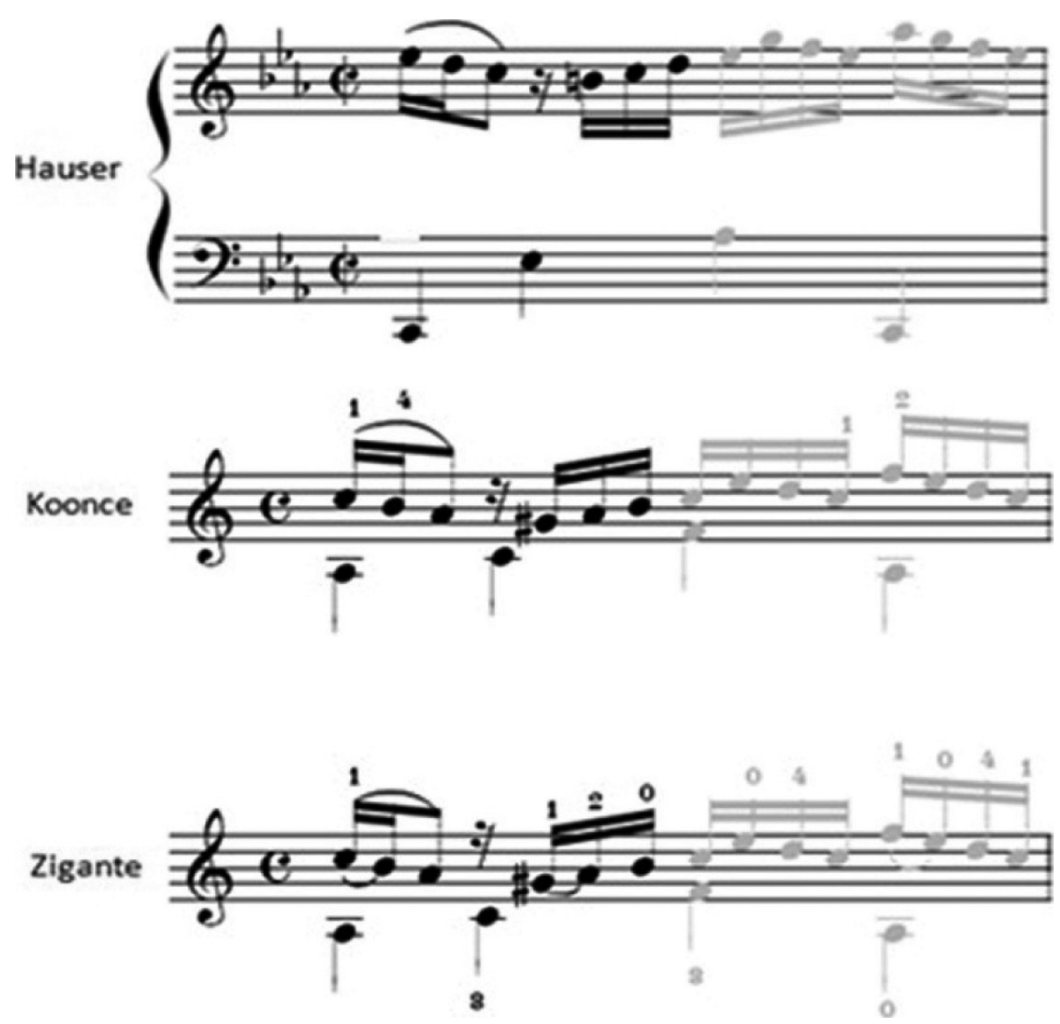

Exemplo 1: Prelúdio BWV 997 de Johann Sebastian Bach - (c. 5) edições apresentando o motivo por movimento escalar - edições para alaúde e violão.

No entanto, apresentamos restrições para tais situações no c. 21. Onde optamos por executar a nota Sol (natural) primeiro tempo em corda solta por uma questão idiomática e a nota de passagem em corda presa devido às questões físicas do instrumento.

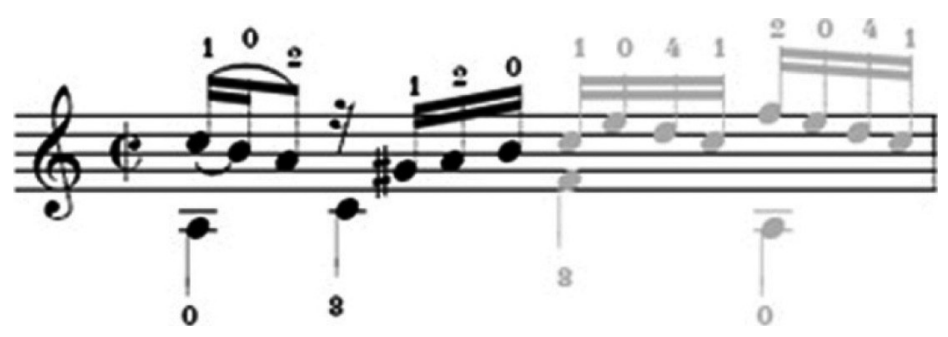

Exemplo 2: Prelúdio BWV 997 de Johann Sebastian Bach - (c. 5) motivo por movimento escalar - edição e digitação nossa.

2) Motivo por movimento escalar e arpejo com apojatura

Nesse motivo optamos por ligar a terceira e segunda células do primeiro e terceiro tempos por entendemos que ao pronunciarmos a nota de passagem, primeiro tempo, ligada, alcançamos uma sonoridade mais "leve” para a nota curta, já que tal nota tem como função a conexão melódica. Logo, no terceiro tempo, também optamos por realizar a apojatura através de um ligado ascendente para que pudéssemos dar ênfase para tal função devido à nota real do arpejo, aparecer realçada no último tempo do compasso.

Outra situação importante que nos levou a tomar tal decisão foi o fato desse motivo aparecer em sequência na obra. Sobre motivos em sequência Alípio e Wolff (2010), descrevem que "[são] motivos que caracterizam uma sequência padronizada de elementos, sejam eles melódicos ou rítmicos [...]” (ALÍPIO; WOLFF, 2010, p. 89). 

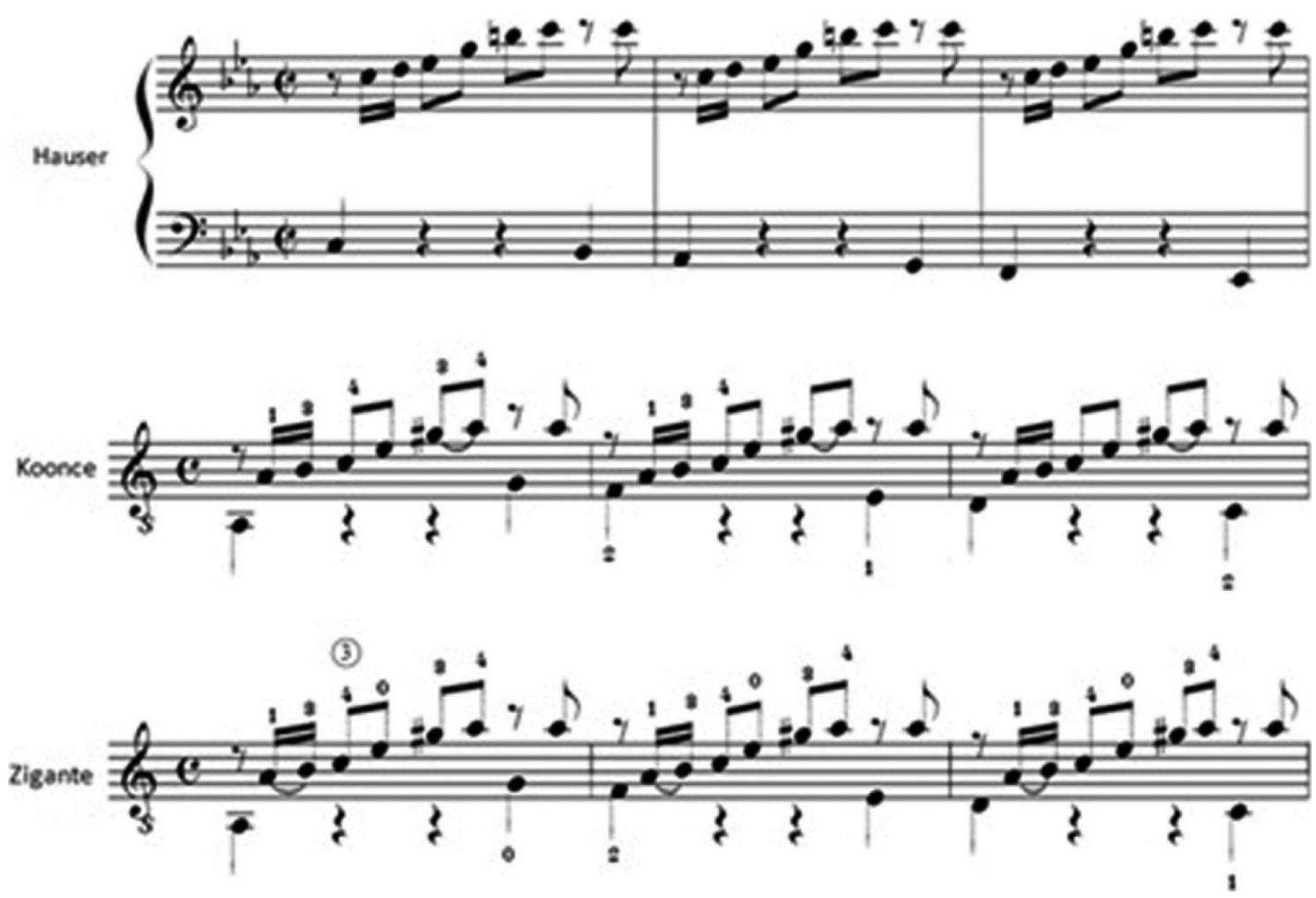

Exemplo 3: Prelúdio BWV 997 de Johann Sebastian Bach - (c. 1 - 3) edições apresentando o motivo por movimento escalar e arpejo com apojatura - edições para alaúde e violão.

Sendo assim, em nossa proposta interpretativa utilizaremos os ligados no primeiro e segundo tempos, devido à edição do autor no trabalho estar em compasso binário. Portanto, ao compararmos as edições de Koonce e Zigante, identificamos que as digitações presente nesses referenciais são semelhantes. Assim, digitamos as notas que compõem a melodia na terceira e primeira cordas, enfatizando o movimento escalar e a apojatura.

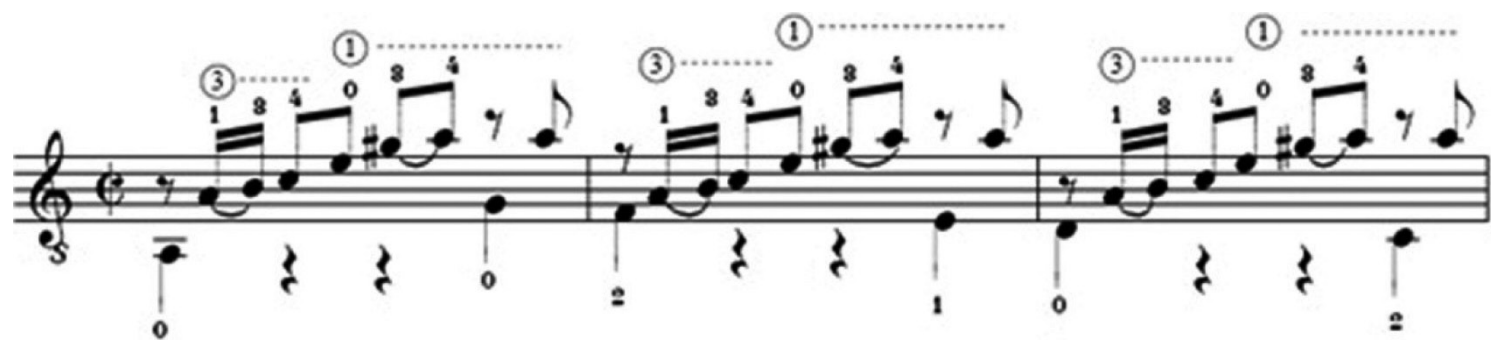

Exemplo 4: Prelúdio BWV 997 de Johann Sebastian Bach - (c.1-3) motivo por movimento escalar e arpejo com apojatura - edição e digitação nossa.

3) Motivo por salto retórico seguido de movimento escalar

Nosso objetivo para esse motivo é apresentar uma digitação que mantenha a polifonia entre a nota do salto retórico e o movimento escalar. Portanto, estamos cientes de que salto retórico e melodia polifônica não são sinônimos, pelo fato de que no salto retórico não existe a entrada de outra linha melódica. Koonce (2005) ${ }^{7}$ relata que "se deve [...] determinar se um salto melódico é um gesto retórico expressivo de uma só voz, ou se ele sinaliza a entrada de uma segunda voz implícita, em diálogo com a primeira”. 

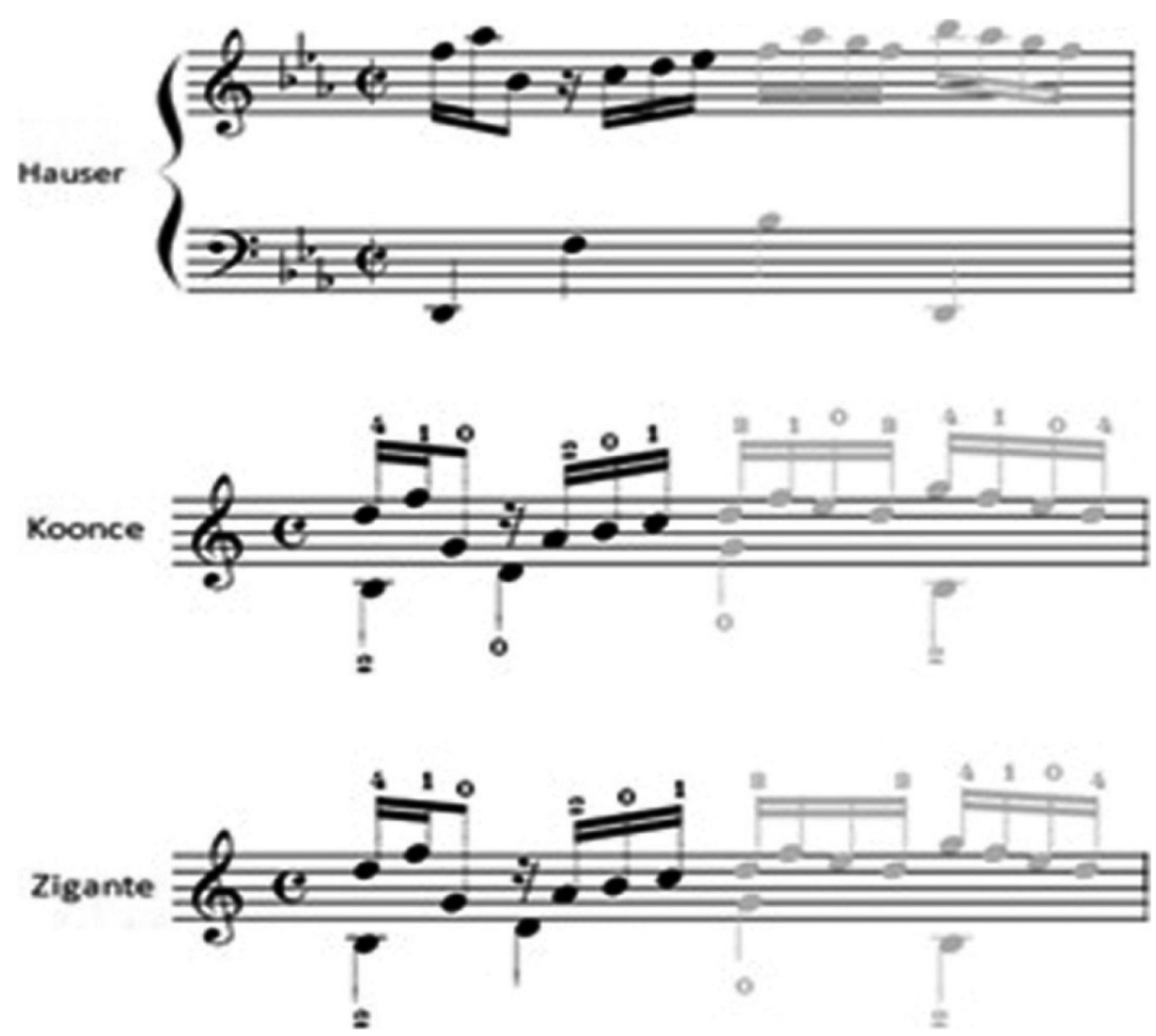

Exemplo 5: Prelúdio BWV 997 de Johann Sebastian Bach - (c. 6) edições apresentando o motivo por salto retórico seguido de movimento escalar - edições para alaúde e violão.

Sendo assim, nossa digitação é semelhante às digitações apresentadas nas edições usadas como referências. Por entendemos que a mesma favorece o prolongamento da nota mais aguda.

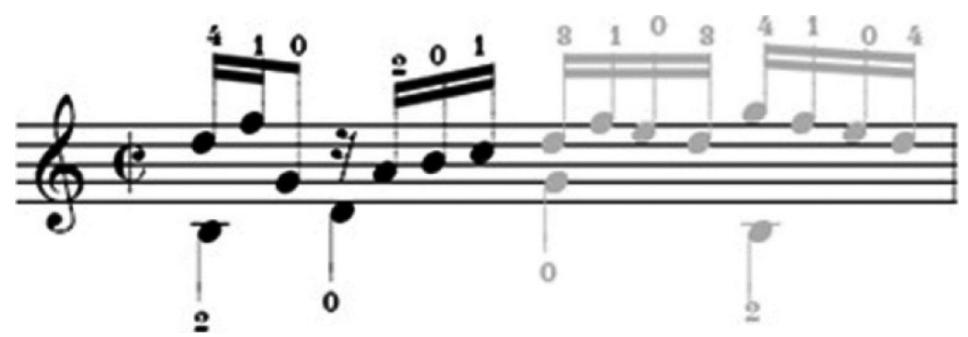

Exemplo 6: Prelúdio BWV 997 de Johann Sebastian Bach - (c. 6) motivo por salto retórico seguido de movimento escalar - edição e digitação nossa.

4) Motivo por bordadura seguido de salto melódico

Para a execução/interpretação deste tipo de motivo, optamos por uma digitação em campanella nas três primeiras células de cada um dos tempos nos cc. 7 - 25 e 36. Já a execução das notas representadas pelo salto melódico, última célula de cada grupo de notas, aparece por momentos na mesma corda ou corda distinta em relação à última nota da sequência em grau conjunto, devido à questão digitacional. Assim, escolhemos um critério que apresentasse unidade ao interpretarmos tais compassos. 

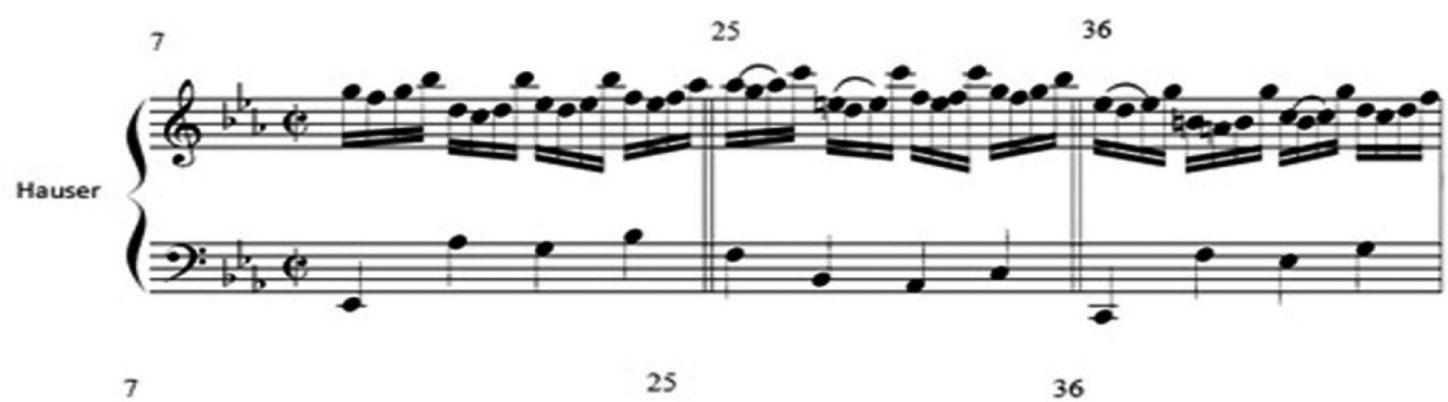

36

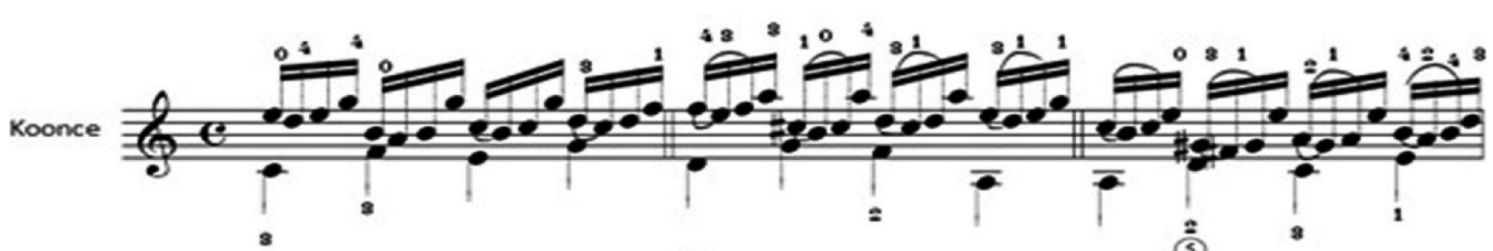

(2)

(5)

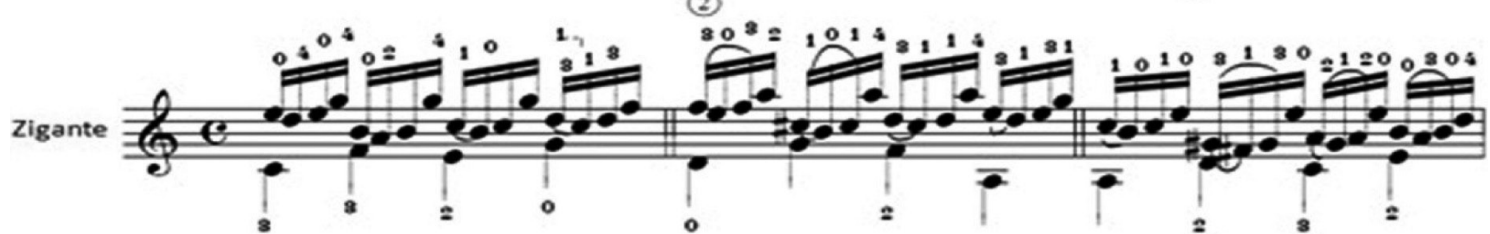

(5)

Exemplo 7: Prelúdio BWV 997 de Johann Sebastian Bach - (c. 7 - 25 e 36) edições apresentando o motivo por bordadura seguido de salto melódico - edições para alaúde e violão.

$\begin{array}{lll}7 & 25 & 36\end{array}$
(3) (1) (3) (2) (2) (3) $\mathrm{C} \mathrm{III-.-}$

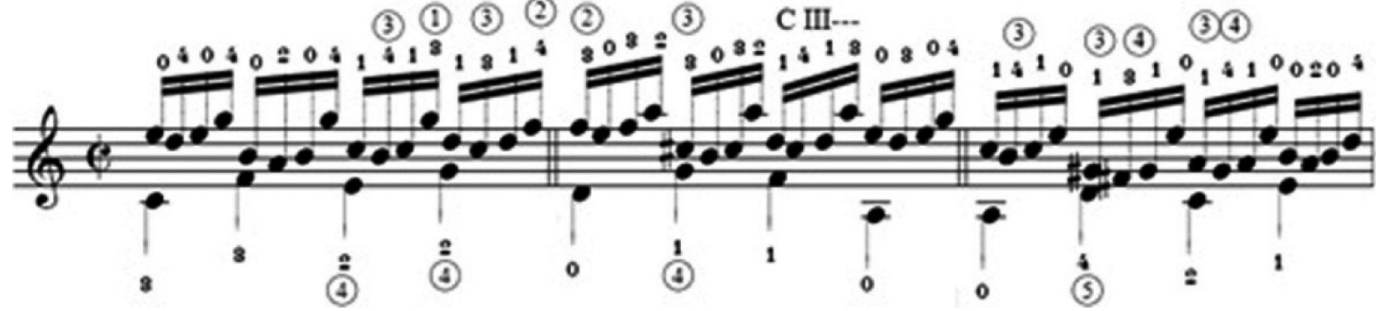

Exemplo 8: Prelúdio BWV 997 de Johann Sebastian Bach - (c. 7 - 25 e 36) motivo por bordadura seguido de salto melódico - edição e digitação nossa.

5) Motivo por pedal

Para a execução/interpretação desse motivo optamos por uma digitação idiomática por questões do contexto digital e mecânico. Outro fator que levamos em consideração é a estrutura do motivo, que é construído por uma sequência com expansão intervalar entre o pedal e as notas representadas em movimento oblíquo. 

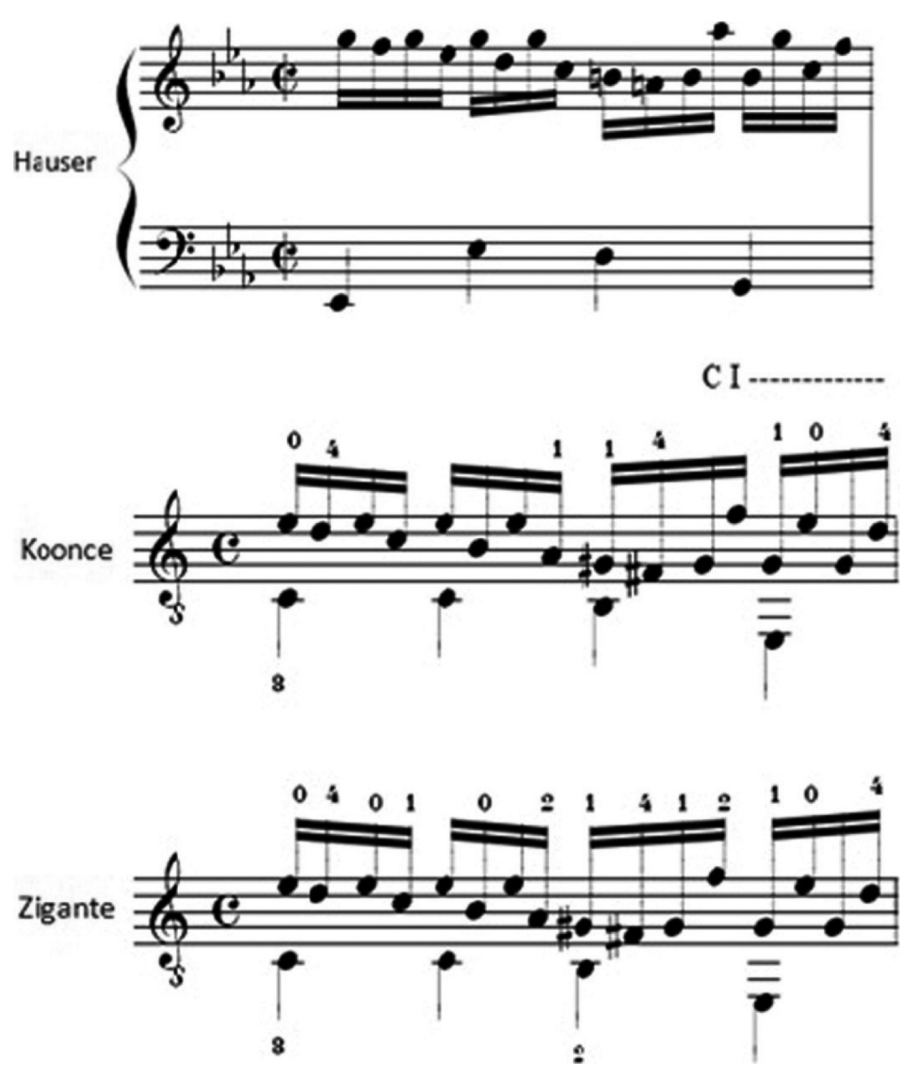

Exemplo 9: Prelúdio BWV 997 de Johann Sebastian Bach - (c. 8) edições apresentando o motivo por pedal edições para alaúde e violão.

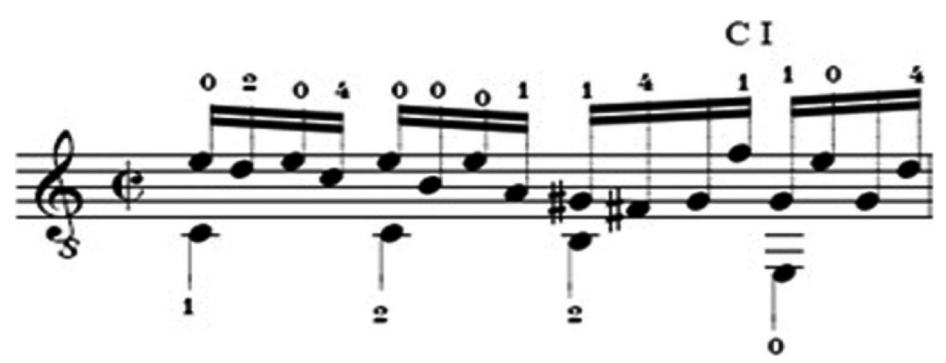

Exemplo 10: Prelúdio BWV 997 de Johann Sebastian Bach - (c. 8) motivo por pedal - edição e digitação nossa.

6) Motivo de ostinato em grau conjunto intercalado por salto retórico

Nesse tipo de motivo, optamos por executar ligada somente a terceira célula do primeiro e terceiro tempos, nas edições de Koonce e Zigante, dos compassos nas quais aparece o "material repetitivo" - ostinato. Primeiramente, para proporcionar mais "leveza” à articulação e consequentemente unidade, pelo fato de tal material ressurgir, nos cc. 40 ao 44 acompanhado da repetição exata de três notas consecutivas na linha do baixo na qual entendemos ser a representação do sogguetto cavatto ${ }^{8}$ (Christus Coronabit Crucigeres), ou seja, o ícone CCC. Sobre esse ícone Fernández, $(2003)^{9}$, relata: “As três notas iniciais do baixo [...] repetidas no começo de cada compasso formam [o] sogguetto cavato do símbolo CCC (Christus Coronabit Crucigeres). Essa é uma representação icônica literal da crucificação”. (FERNÁNDEZ, 2003, p. 74) 

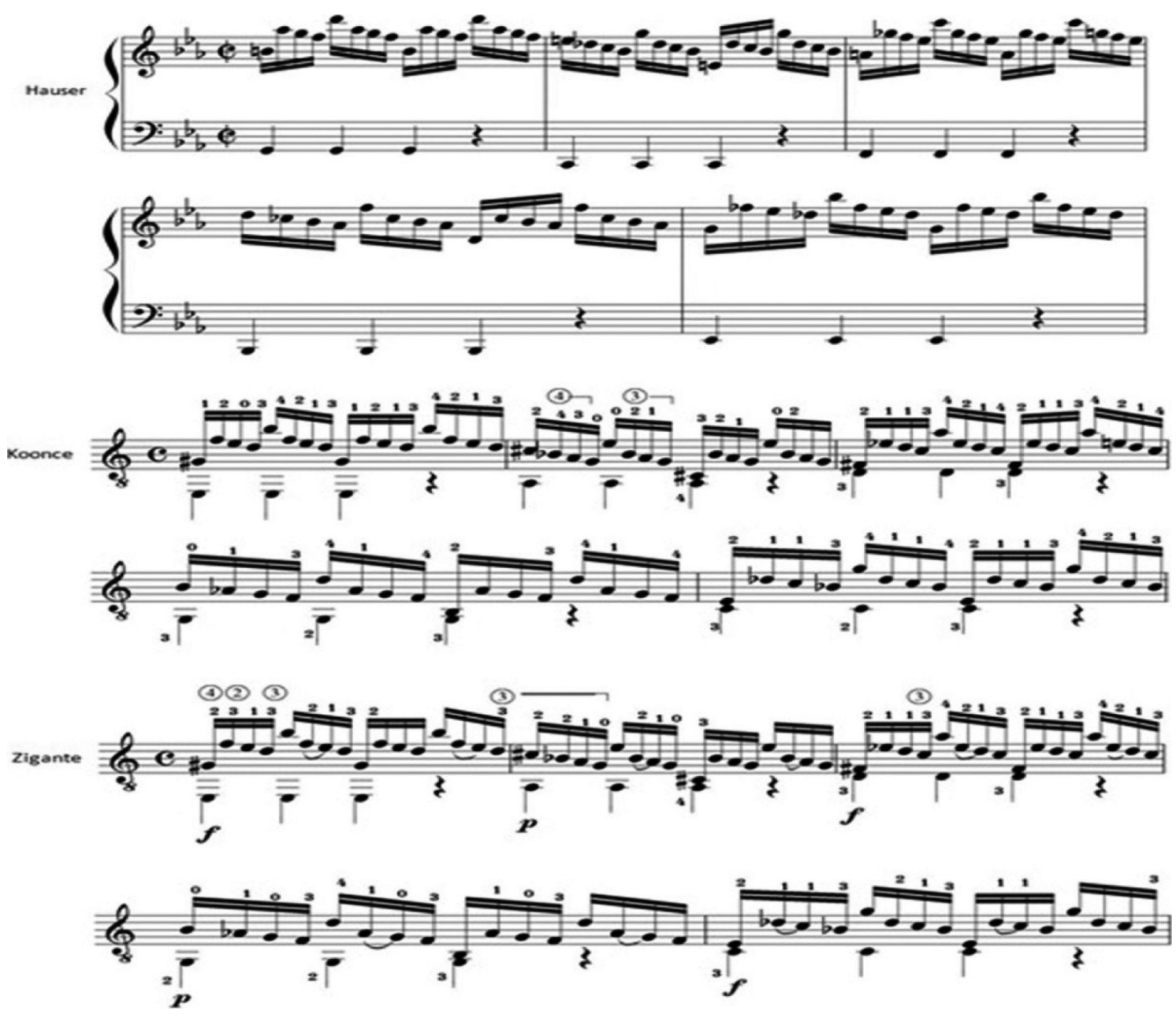

Exemplo 11: Prelúdio BWV 997 de Johann Sebastian Bach - (c. 40 - 44) motivo de ostinato em grau conjunto intercalado por salto retórico - edições para alaúde e violão.
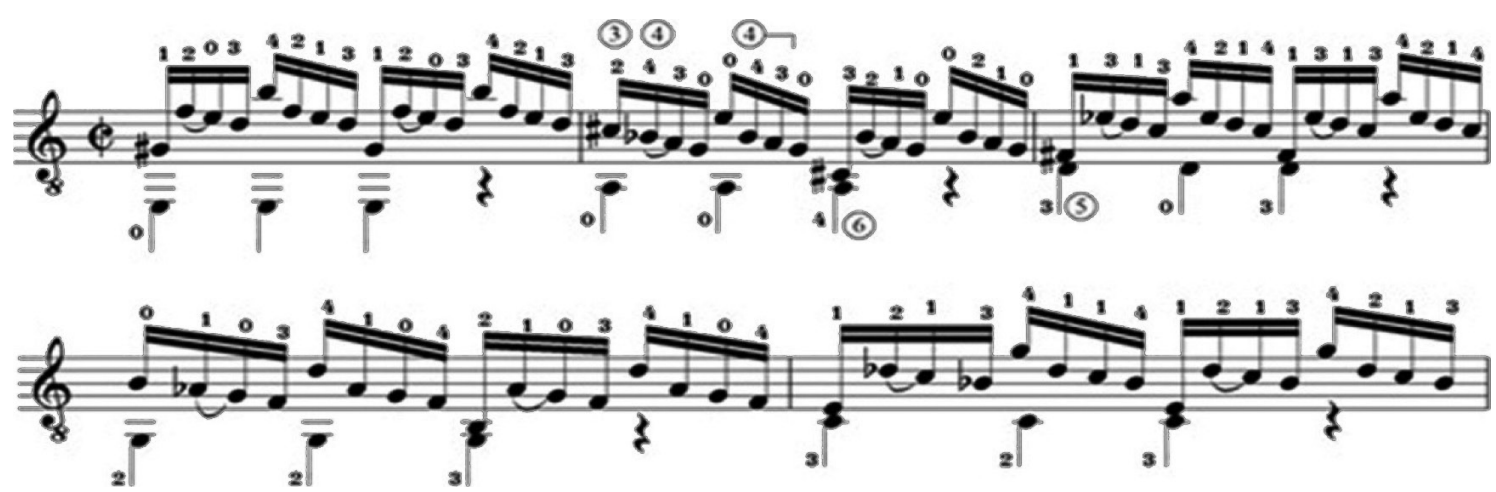

Exemplo 12: Prelúdio BWV 997 de Johann Sebastian Bach - (c. 40 - 44) motivo de ostinato em grau conjunto intercalado por salto retórico - edição e digitação nossa.

Assim, ao compararmos os trechos das edições, nas quais esse motivo aparece, identificamos que Koonce não propõem ligados, entretanto Zigante propõe ligados em diferentes notas e tempos dos compassos nas quais esse motivo aparece. Em nossa edição pelo fato de apresentar-se em compasso binário, propomos os ligados sempre da segunda para terceira célula do primeiro e segundo tempos, das situações em que lembramos tal motivo. 


\section{Considerações finais}

Ao identificarmos e classificarmos os elementos musicais, elaboramos uma digitação que refletisse lógica e unidade utilizando-se dos seguintes critérios.

Motivo por movimento escalar - aconselhamos a execução através do ligado; motivo por movimento escalar e arpejo com apojatura - nesse, optamos por apresentar ligado e manter um padrão digitacional; motivo por salto retórico seguido de movimento escalar - aqui, buscamos uma digitação que desse ênfase à polifonia; motivo por bordadura seguido de salto melódico - elegemos, priorizar o requisito campanella; motivo por pedal - para esse, escolhemos uma digitação idiomática preservando a relação intervalar entre a nota pedal e as notas em movimento oblíquo e motivo de ostinato em grau conjunto intercalado por salto retórico - onde frisamos o requisito articulação.

Por entendermos que a digitação é um elemento interpretativo, escolhemos tais critérios para executarmos os motivos presentes nessa obra musical. Porém, se fôssemos elaborar digitações em outras obras musicais com características semelhantes poderíamos empregar tais princípios ou propor outras formas de executar os motivos musicais.

\section{Notas}

1 Utilizamos tal nomenclatura baseado em Alípio (2014, p. 50).

2 O EI parte de um problema (foco ou objeto) de execução, ou seja, um resultado ou conteúdo interpretado na obra. Em continuidade, propõe a solução técnico-instrumental como meio para a realização de uma idéia ou, em outras palavras, propõe uma decisão interpretativa. (PIRES JR, 1998, p. 79).

3 http://tudigit.ulb.tu-darmstadt.de/show/Mus-Ms-1322/0002

4 É a repetição de uma estrutura melódica, em altura diferente, nas quais manten-se as mesmas relações intervalares.

5 Salto retórico é um saltus duriusculus, termo definido por Bernhard (século XVII e XVIII) como intervalo melódico dissonante, geralmente com sentido de exclamação. (BUELOW, 1989, apud ALÍPIO, 2004, p. 118)

${ }^{6}$ Refere-se aqui às notas repetidas que aparecem alternando-se com as notas em grau conjunto e em movimento oblíquo.

7 Must [...] determine whether a melodic leap is an expressive rhetorical gesture of a single voice or whether it signals the entrance of a second, implied, voice in dialog with the first.

8 São palavras que representam um motivo musical.

9 Las tres notas iniciales del bajo [...] repetidos lal comienzo de cada compás, [o] forman sogguetto cavato: El símbolo CCC (Christus Coronabit Crucigeres). Es esto uma representación icónica literal de la cruxifixión.

\section{Referências}

ALÍPIO, Alisson; WOLFF, Daniel. O processo de digitação para violão da Ciaccona BWV 1004 de Johann Sebastian Bach. Opus, Goiânia, v. 16, n. 2, p. 80-101, dez. 2010.

ALÍPIO, Alisson. Teoria da digitação: Um protocolo de instâncias, princípios e perspectivas para a construção de um cenário digitacional ao violão. $184 \mathrm{f}$. Tese (Doutorado em Música) - Instituto de Artes, Universidade Federal do Rio Grande do Sul, Porto Alegre, 2014.

BARCELÓ, Ricardo. La Digitación Guitarrística, recursos pocos usuales. Madri: Real Musical, 1995.

CARLEVARO, Abel. Escuela de la guitarra exposición de la teoría instrumental. Buenos Aires, Barry editorial, 1979. 
COLOMBO, Thiago; WOLFF, Daniel. As ligaduras longas na Ciaccona em ré menor BWV 1004 de J. S. Bach e sua adaptação em transcrição para violão. Artigo publicado na Música Hodie - Revista do Programa de Pós-Graduação em Música da Universidade Federal de Goiânia, vol. 6, n. 2, Goiânia, 2006. Disponível em:<http://www.danielwolff.com.br/arquivos/File/articulacao_bach.htm> Acesso em 14/03/2014.

CONTRERAS, Antônio. La Técnica de David Russell en 165 consejos. Sevilla, Ed. Cuadernos Abolays, 1998.

FERNÁNDEZ, Eduardo. Técnica, mecanismo y aprendizaje: una investigación sobre como llegar a ser guitarrista. Ediciones Art-Montevideo - Uruguay, 2000.

FERNÁNDEZ, Eduardo. Ensayos sobre las obras para laúd de J. S. Bach. Uruguay: Art Ediciones, Primeira edición 2003.

KOONCE, Frank. Articulation, Texture, and Voicing. 2005-Disponível em: <http://www.frankkoonce.com/articles/Articulation,\%20Texture,\%20and\%20Voicing.pdf $>$. Acesso em: 09/09/2013.

NUNES, Maurício. Análise da digitação no Ballet de Ponce: Contraponto, Vibrato, Prolongação de Notas, Translado e Timbre. 40 f. Trabalho de Conclusão de Curso (Graduação em Música) Conservatório de Música, Universidade Federal de Pelotas, 2007.

ORELLANA, Adriano Alexandre Rivas. Digitação violonistica - Uma análise crítica e musical das transcrições de Andrés Segovia e Frank Koonce da Fuga BWV 998 de J. S. Bach. Trabalho apresentado ao II Simpósio Acadêmico de Violão da Embap, de 6 a 11 de outubro de 2008.

PIRES JÚNIOR, José Homero. Construção e Função de Exercícios Integrados na Execução Violonistíca. 200 f. Dissertação (Mestrado em Música) - Instituto de Artes, Universidade Federal do Rio Grande do Sul, Porto Alegre, 1998.

SANTOS, Cristiano Souza dos. Processos de Criação do Intérprete: Estudos de dedilhados na Aquarelle de Sérgio Assad. 99 f. Dissertação (Mestrado em Música) - Escola de Música da Universidade Federal da Bahia, Salvador, 2009.

SILVEIRA FILHO, Fernando. Uma Análise da Digitação Grafada nas Five Bagatelles de William Walton. 67 f. Dissertação (Mestrado em Música) - Instituto de Artes, Universidade Federal do Rio Grande do Sul, Porto Alegre, 2004.

WOLFF, Daniel. Como digitar uma obra para violão. Artigo publicado na Revista Violão Intercâmbio no 46, São Paulo, 2001. Disponível em: <http://www.danielwolff.com.br/arquivos/File/ Como_Digitar_Port.htm>. Acesso em: 09/09/2013.

\section{Gravações}

BONELL, Carlos. Fandango: Purcell. Bach. Sanz. Tárrega. Sor. Pujol. Rodrigo. CD. Compact disc digital audio, 1990.

GALBRAITH, Paul. Bach Lute Suites, BWV 995 - 998. CD.

WILLIAMS, John. Bach: the for lute suites, John Williams, guitar. CD. 


\section{Edições}

HAUSER. BWV 997. Suite c-moll: Prelude - Fuga - Sarabande - Gigue - Double. Disponível em: $<$ http://tudigit.ulb.tu-darmstadt.de/show/Mus-Ms-1322/0002>. partitura. Acesso em: 17/06/2014.

KOONCE. Frank. The Solo Lute Works of Johann Sebastian Bach. Editor Printed in U.S.A, 134 f. partitura - KJOS West, 4380 Jutland Drive, San Diego, Califórnia,1989.

ZIGANTE, Frédéric. Bach: dal liuto alla chitarra Le opere per Liuto di Johann Sebastian Bach, 124 f. partitura, complete lute music - Transcription for guitar by Frédéric Zigante. Guitar, 2001.

Mauricio Nunes - Bacharel em violão pelo Conservatório de Música da Universidade Federal de Pelotas - UFPEL e Pós-graduado (Especialização) pela Escola de Música e Belas Artes do Paraná - UNESPAR. Atualmente, é professor de violão no Conservatório de Música de Ponta Grossa-PR e professor de violão no Centro da Juventude em Castro-PR.

Alisson Alípio - Doutor e Mestre em Música (Práticas Interpretativas - violão) pela Universidade Federal do Rio Grande do Sul (UFRGS) e Bacharel em Música (Superior de Instrumento - violão) pela Escola de Música e Belas Artes do Paraná (EMBAP). Tem experiência na área de Música, atuando principalmente nos seguintes temas: interpretação musical, pedagogia do violão e metodologia da pesquisa científica em música. É concertista e professor adjunto da cadeira de violão da Universidade Estadual do Paraná (UNESPAR) - Campus EMBAP. 